\title{
ARTICLE
}

\section{Years of SINBAD (Shielding Integral Benchmark Archive and Database)}

\author{
Ivan Kodeli $^{\mathrm{a}^{*}}$, Alberto Milocco ${ }^{\mathrm{b}}$, Pedro Ortego ${ }^{\mathrm{c}}$ and Enrico Sartori ${ }^{\mathrm{d}}$ \\ ${ }^{a}$ Jožef Stefan Institute, Jamova 39, 1000 Ljubljana, Slovenia; ${ }^{b}$ Università degli Studi di Milano - Bicocca, Italy; ' SEA Shielding, \\ Avda Atenas 75, Las Rozas, 28230 Madrid, Spain; ${ }^{~}$ retired from OECD/NEA Data Bank, Bd. Des Iles, \\ 92130 Issy-les-Moulineaux, France
}

\begin{abstract}
The SINBAD project started in the early 1990's as a collaboration between the Organization for Economic Cooperation and Development's Nuclear Energy Agency Data Bank (OECD/NEADB) and the Radiation Safety Information Computational Center (RSICC) at the Oak Ridge National Laboratory (ORNL) with the goal to preserve the information on the performed radiation shielding benchmarks and make them available in a standardised form to the international community. The SINBAD database comprises now 100 shielding benchmarks, covering fission reactor shielding, fusion blanket neutronics, and accelerator shielding. A thorough revision of the SINBAD benchmark experiments was undertaken recently in order to verify the completeness and consistency of the benchmark information, in particular concerning the evaluation of the experimental sources of uncertainty. New improved computer code models were prepared. This review process is expected to provide users with an easier choice and help them make better use of the experimental information. The OECD NEA Working Party on Scientific Issues of Reactor Systems (WPRS) Expert Group on Radiation Transport and Shielding (EGRTS) was started in 2011 with the mandate among others, to monitor, steer and support the continued development of the SINBAD database. SINBAD is available from RSICC and from the NEA Data Bank.
\end{abstract}

Keywords: shielding benchmark experiments; fission; fusion; accelerators

\section{Introduction}

With the goal to preserve and make available the information on the performed radiation shielding benchmarks the Organization for Economic Cooperation and Development's Nuclear Energy Agency Data Bank (OECD/NEADB) and the Radiation Safety Information Computational Center (RSICC) at Oak Ridge National Laboratory (ORNL) started about 20 years ago the Shielding Integral Benchmark Archive and Database (SINBAD) project [1-5]. The database is intended for different users, including nuclear data evaluators, computer code developers, experiment designers and university students.

In 2012 the round number of 100 shielding benchmarks in the SINBAD collection was reached. The benchmarks are divided into three categories, covering both low and inter-mediate energy particles applications: fission reactor shielding (46 benchmarks), fusion blanket neutronics (31), and accelerator shielding (23) benchmarks. In addition to the characterization of the radiation source, description of the experimental set-up, instrumentation and detectors, most sets in SINBAD contain also the deterministic or probabilistic (Monte Carlo) radiation transport computer model used for the

*Corresponding author. Email: ivan.kodeli@ijs.si interpretation of the experiment and, where available, results from uncertainty analysis. The set of primary documents used for the benchmark compilation and evaluation are provided in computer readable form.

\section{Revision and quality assessment}

In the past the main effort was devoted to the collection and preservation of the experimental information, while keeping the format as simple (i.e. cheap for maintenance) as possible. Since the experimental data presently available in SINBAD are of varying quality, a thorough revision and classification of the benchmark experiments was undertaken recently in order to provide users with an easier choice and help them make better use of the experimental information. Up to now the review was concluded for 34 benchmark experiments, mostly of relevance for fusion neutronics and for accelerator shields. Further 11 benchmarks are currently being revised and reclassified.

The OECD NEA Working Party on Scientific Issues of Reactor Systems (WPRS) Expert Group on Radiation Transport and Shielding (EGRTS) was started in 2011 with the mandate among others, to monitor, steer and support the continued SINBAD development. 
Table 1. SINBAD fission and fusion benchmarks with review process completed. Main domains requiring further attention and additional information needed are listed.

\begin{tabular}{|c|c|c|}
\hline Benchmark & Improvement & Additional information needed on \\
\hline NESDIP-2 & - new MCNP model & $\begin{array}{l}\text { - activation foils positioning \& housing } \\
\text { - background subtraction method }\end{array}$ \\
\hline NESDIP-3 & - new detailed MCNP model & $\begin{array}{l}\text { - activation foils positioning } \& \text { housing } \\
\text { - background subtraction method }\end{array}$ \\
\hline JANIS-1 & - new detailed MCNP model & $\begin{array}{l}\text { - activation foils positioning \& housing } \\
\text { - background subtraction method }\end{array}$ \\
\hline JANIS-8 & - new detailed MCNP model & $\begin{array}{l}\text { - activation foils positioning \& housing } \\
\text { - background subtraction method }\end{array}$ \\
\hline HARMONIE & 1 & - geometry, materials and neutron source \\
\hline OKTAVIAN W & $\begin{array}{l}\text { - new routine \& detailed MCNP model } \\
\text { - benchmark data evaluation }\end{array}$ & $\begin{array}{l}\text { - background subtraction method } \\
\text { - } \gamma \text { source measurements } \\
\text { - } \gamma \text { detector response function }\end{array}$ \\
\hline FNS W & $\begin{array}{l}\text { - new detailed MCNP model } \\
\text { - benchmark data evaluation }\end{array}$ & $\begin{array}{l}\text { - unfolding technique of NE-213 measurements } \\
\text { - activation foils positioning, uncertainty \& housing }\end{array}$ \\
\hline FNG W & re-evaluation of benchmark source term & I \\
\hline FNG/TUD W & re-evaluation of benchmark source term & $\begin{array}{l}\text { - neutron \& } \gamma \text { flux point-wise uncertainties } \\
\text { - measured pulse-height distributions } \\
\text { - inconsistencies with FNG-W bench.results }\end{array}$ \\
\hline OKTAVIAN Si 60cm & $\begin{array}{l}\text { - new routine \& detailed MCNP model } \\
\text { - benchmark data evaluation }\end{array}$ & $\begin{array}{l}\text { - background subtraction method } \\
\text { - } \gamma \text { source measurements \& detector response function }\end{array}$ \\
\hline OKTAVIAN Si 40cm & - new routine \& detailed MCNP model & $\begin{array}{l}\text { - neutron flux measurements only available in graphical } \\
\text { form }\end{array}$ \\
\hline "OKTAVIAN Ni & - new routine MCNP model & 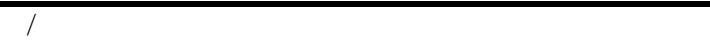 \\
\hline FNS Graphite & - new detailed MCNP model & $\begin{array}{l}\text { - experimental unfolding technique, } \\
\text { - activation foils positioning \& housing }\end{array}$ \\
\hline FNG SiC & - neutron source re-evaluation & 1 \\
\hline FNG/TUD SiC & - re-evaluation of benchmark source term & $\begin{array}{l}\text { - neutron \& } \gamma \text { flux point-wise uncertainties } \\
\text { - original pulse-height distributions } \\
\text { - inconsistencies with FNG-SiC benchmark results }\end{array}$ \\
\hline FNS V & $\begin{array}{l}\text { - new detailed MCNP model } \\
\text { - benchmark data evaluation }\end{array}$ & $\begin{array}{l}\text { - experimental unfolding technique } \\
\text { - activation foils positioning, uncertainty \& housing }\end{array}$ \\
\hline OKTAVIAN Al & $\begin{array}{l}\text { - new routine \& detailed MCNP model } \\
\text { - benchmark data evaluation }\end{array}$ & $\begin{array}{l}\text { - neutron flight path parameter } \\
\text { - background subtraction method } \\
\text { - } \gamma \text { source measurements } \& \gamma \text { detector response function }\end{array}$ \\
\hline " OKTAVIAN Fe & - new routine MCNP model & " - very large measurement uncertainties \\
\hline FNS Iron dogleg-duct & 1 & $\begin{array}{l}\text { - neutron source spectrum } \\
\text { - neutron detector response function }\end{array}$ \\
\hline TUD Iron slab & - new routine MCNP model & - neutron source \\
\hline FNG Stainless Steel & - neutron source re-evaluation & $\begin{array}{l}\text { - a comprehensive geometry description would be } \\
\text { helpful }\end{array}$ \\
\hline FNG ITER Dose Rate & - neutron source re-evaluation & 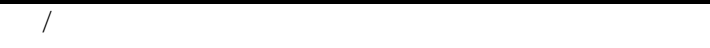 \\
\hline FNG/TUD ITER Bulk & - neutron source re-evaluation & $\begin{array}{l}\text { - neutron and gamma flux point-wise uncertainties } \\
\text { - original pulse-height distributions }\end{array}$ \\
\hline FNG ITER Bulk & - neutron source re-evaluation & 1 \\
\hline FNG ITER streaming & - neutron source re-evaluation & 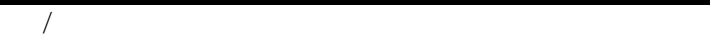 \\
\hline FNS Oxygen & & - neutron effective flight path parameter \\
\hline FNS Sky-shine & & - neutron source spectrum \\
\hline IPPE-V shells, $14 \mathrm{MeV} \mathrm{n}$ & \multirow[t]{2}{*}{ New 2D \& 3D MCNP5 models prepared } & \\
\hline IPPE-Fe shells, $14 \mathrm{MeV} \mathrm{n}$ & & \\
\hline $\begin{array}{l}\text { IPPE-Th shell with } 14 \\
\text { MeV \& }{ }^{252} \mathrm{Cf} \text { neutron } \\
\text { source }\end{array}$ & 2D\&3D MCNP5 models prepared & $\begin{array}{l}\text { more details on collimator and detector needed, } \\
\text { experimental bare }{ }^{252} \mathrm{Cf} \text { source spectra not available, }\end{array}$ \\
\hline
\end{tabular}




\begin{tabular}{|l|l|l|}
\hline $\begin{array}{l}\text { IPPE-Bi shells with 14 } \\
\text { sev \& }{ }^{252} \text { Cf neutron }\end{array}$ & $\begin{array}{l}\text { collimator and detector housing needed, bare }{ }^{252} \mathrm{Cf} \\
\text { source spectra not available }\end{array}$ \\
\hline $\begin{array}{l}\text { MSU 155 MeV/nucleon } \\
\text { He \& C ions on Al } \\
\text { targets }\end{array}$ & MCNPX model prepared & $/$ \\
\hline $\begin{array}{l}\text { Tokyo Uni. transmission } \\
\text { of 52MeV protons } \\
\text { through C, Fe, H2O \& } \\
\text { concrete }\end{array}$ & MCNPX model prepared & $\begin{array}{l}\text { experimental information should be recovered; } \\
\text { experimental uncertainty needed on: proton energy, } \\
\text { density, H content in concrete, unfolding process }\end{array}$ \\
\hline $\begin{array}{l}\text { ISIS 800 MeV protons } \\
\text { (120cm Concrete \& } \\
\text { 60cm Iron) }\end{array}$ & MCNPX model prepared & $/$ \\
\hline $\begin{array}{l}\text { HIMAC 400 MeV/nucl. } \\
\text { C ions on concrete shield }\end{array}$ & PHITS model prepared & $\begin{array}{l}\text { reduction in unfolding uncertainty, estimate of } \\
\text { experimental uncertainty should be obtained before } \\
\text { these experiments could be used for benchmarking } \\
\text { processes }\end{array}$ \\
\hline $\begin{array}{l}\text { HIMAC 400 MeV } \\
\text { nucleon C ions on Fe } \\
\text { shield }\end{array}$ & PHITS model prepared \\
\hline $\begin{array}{l}\text { HIMAC 100-800 } \\
\text { MeV/nucleon heavy ions }\end{array}$ & MCNPX model prepared & and parameter uncertainties needed, \\
\hline
\end{tabular}

The objective of the thorough review and classification of the benchmarks included in SINBAD was to verify, and if possible, to extend the usage of the experiments for modern nuclear data validation, and to assist the users in the selection of the benchmarks from the database. The main criteria of the review were the completeness and the consistency of the information, in particular concerning the evaluation of the experimental sources of uncertainty. These concern the experimental setup, the neutron source specifications, the detector resolution, the geometry and precise material composition of the components [6-9]. The procedure used to derive the experimental data (unfolding) was examined in order to limit as much as possible the impact of processing of the measured data and to assure the data referred as measured do not include unnecessary processing approximations.

Table 1 lists the SINBAD experiments that have been subjected to the review process, the improvements and the outcomes of the assessment for any of them.

The review started with the review of several Time-of-Flight (TOF) experiments in order to determine the usefulness of these benchmarks for the validation of today's high quality nuclear data evaluations and computer codes [6-8]. It was recommended that the good practice of providing TOF spectra, in addition to energy spectra (as done for IPPE-Bi Shell experiment) as well as an explicit modelisation of the collimator-detector system and of the neutron source should be encouraged and extended to any TOF experiment in SINBAD [6]. Improved MCNP models, including time domain calculations have been prepared . Simpler MCNP models for fast routine calculations rely on the measured bare source spectrum (used as response function) and approximate detector system. The detailed 3D models include the collimator, detector housing and a re-evaluation of the neutron source term. The D-T neutron source subroutine for the MCNP-5 and MCNP-X codes was revised. The room return effects can be available from the latter detailed models. With the new models, semi-qualitative sensitivity and uncertainty analyses have been pursued on the benchmark data to evaluate the impact of various approximations [7].

After a careful examination of the available description of the benchmark set-up and of the measured quantities including the associated uncertainties the suitability of the benchmarks for nuclear data and computer code validation purposes, as well as for education and training purposes was concluded. If the available information is found to be inconsistent or not complete a detailed list of incomplete or missing information is provided. The special and interesting features of the benchmark are listed explicitly.

In particular we believe it to be important to describe in details the drawbacks observed in the benchmark description and point out the missing or incomplete information. We hope that a detailed list of the additional information needed from the experimentalists and evaluators will encourage providing these data.

\section{Conclusion}

The SINBAD database currently contains compilations and evaluations of experiments for 46 reactor shielding problems, 31 for fusion neutronics shielding and 23 for accelerator shielding cases. Several new experiments were compiled and need final review. A revision and classification of the benchmark experiments according to the completeness and reliability of information is being undertaken in order to help users making the appropriate choice of the 
experimental information. A series of experiments have already, or are currently being revised and reclassified. The SINBAD database is now widely used for code and data validation. Materials covered include: Air, N. O, $\mathrm{H}_{2} \mathrm{O}, \mathrm{Al}, \mathrm{Be}, \mathrm{Cu}$, graphite, concrete, $\mathrm{Fe}, \mathrm{Pb}, \mathrm{Li}, \mathrm{Ni}, \mathrm{Nb}$, $\mathrm{SiC}, \mathrm{Na}, \mathrm{SS}, \mathrm{W}, \mathrm{V}$ and mixtures thereof. Over 40 organisations from 14 countries and 2 international organisations have contributed data and work in support of SINBAD. Improvement of comprehensiveness of the databases, experiment re-interpretation and re-evaluation using state-of-the-art methods will require a large further effort and all laboratories wishing to manage and share this knowledge are invited to contribute. The setting up of a review team within the scope of the OECD/NEA Expert Group on Radiation Transport and Shielding (EGRTS) is foreseen.

\section{Acknowledgements}

The authors wish to thank all the contributors to the SINBAD project and the participants of the EGRTS. The quality assessment of the SINBAD experiments was supported by the Ministry of Science of Slovenia and the OECD/NEA Data Bank.

\section{References}

[1] P. Miller, P. Nagel, M. Salvatores and E. Sartori, Shielding Experimental Benchmark Base at the Nuclear Energy Data Bank, Proc $7^{\text {th }}$ Int. Conf. on Rad. Shielding, Bournemouth, UK (1988) NEACRP-L-310.

[2] A.K. McCracken and E. Sartori, A Proposed Structure for a Shielding Experimental Benchmark Data Bank, Report NEACRP-A-1020, OECD/NEA
(1989).

[3] H. T. Hunter, D. T. Ingersoll, R. W. Roussin, C. O. Slater, E. Sartori and I. Kodeli, SINBAD-Shielding Integral Benchmark Archive and Database, Proc. ANS Topical Meeting on Rad. Prot. \& Shielding, Cape Cod, Massachusetts (1996).

[4] I. Kodeli, E. Sartori and B. Kirk, Recent accelerator experiments updates in Shielding INtegral Benchmark Archive Database (SINBAD), Nuclear Instruments and Methods in Physics Research A 562 (2006), pp.725-728.

[5] I. Kodeli, E. Sartori and B. Kirk, SINBAD Shielding benchmark experiments status and planned activities, Proc. ANS $14^{\text {th }}$ Biennial Topical Meeting of Rad. Protection \& Shielding Division, Carlsbad, New Mexico, USA, April 3-6, 2006.

[6] I. Kodeli, A. Milocco and A. Trkov, Lessons learned from the TOF-Benchmark intercomparison exercise within EU Conrad project (How not to misinterpret a TOF-Benchmark), Nuclear Technology, Vol. 168 (Dec. 2009), pp.965-969.

[7] A. Milocco, A. Trkov and I. Kodeli, The OKTAVIAN TOF experiments in SINBAD: Evaluation of the experimental uncertainties, Annals of Nuclear Energy 37 (2010), pp.443-449.

[8] A. Milocco, I. Kodeli and A. Trkov, The 2010 compilation of SINBAD: Quality assessment of the fusion shielding benchmarks, Proc. NEMEA-6 Scientific workshop on Nuclear Measurements, Evaluations and Application, Krakow, Poland, 25-28 Oct. 2010.

[9] B. L. Kirk, R. E. Grove, I. Kodeli, J. Gulliford and E. Sartori, Shielding Integral Benchmark Archive and Database (SINBAD), Journal of ASTM International (JAI), 9 (March 2012), Iss. 3, pp.8. 